\title{
Peningkatan Pengetahuan Jurnalistik Siswa SMA Kota Medan Melalui Pemanfaatan Smartphone
}

\author{
Corry Novrica AP Sinaga \\ Universitas Muhammadiyah Sumatera Utara \\ Email: corrynovrica@umsu.ac.id
}

\begin{abstract}
Smartphones make widely opportunity for us to practice the science of journalism. Anyone can cover and then spread the news. Through various social media applications, everyone can become a reporter, deliver news to friends, spread it, and then share the news to everyone. The results of research on smartphone utilization in improving journalistic skills to 40 students of SMA Negeri 4 Medan and 36 student of SMA Kartika I-2 Medan, the pre test showed, 95\% of 10th grade students is a smartphone user with a usage period of 3 to 5 years. Because of that the students are used to taking photos and making videos with their smart phones. But its naturally is only for personal consumption and technically, the results are not good for journalistic activities. But after being given journalistic introduction training by using a smartphone, for 2 days, the post test results showed an increase in students' knowledge, about techniques for taking photos and videos of humans, objects and other moving objects, for journalistic purposes. In addition, students also recognize the existence of Citizen Journalism, citizen journalism.
\end{abstract}

\section{Key Word: Smartphone, Journalism, Students}

\begin{abstract}
Abstrak
Kehadiran ponsel pintar atau smartphone memperluas kesempatan kepada khalayak untuk mempraktekkan ilmu jurnalistik. Siapapun bisa meliput dan kemudian menyebarluaskan berita. Lewat berbagai aplikasi sosial media setiap orang bisa menjadi pewarta, menyampaikan kabar pada lingkaran perkawanannya yang kemudian menyebar apabila mereka yang menerima kabar kemudian turut berbagi berita. Hasil penelitian tentang pemanfaatan smartphone dalam meningkatkan kemampuan jurnalistik kepada 40 orang siswa SMA Negeri 4 Medan dan 36 orang SMA Kartika I-2 Medan, hasil pre test menunjukkan, $95 \%$ siswa kelas 10 di SMA Negeri 4 Medan dan siswa SMA Kartika I-2 Medan, adalah pengguna smartphone dengan jangka waktu pemakaian 3 hingga 5 tahun. Karena itu para siswa sudah terbiasa mengambil poto dan membuat video dengan ponsel pintar mereka. Namun sifatnya hanya untuk konsumsi pribadi dan secara teknis, hasilnya tidak maksimal untuk aktifitas jurnalistik. Namun setelah diberikan pelatihan pengenalan jurnalistik dengan memanfaatkan smartphone, selama 2 hari, hasil post test menunjukkan peningkatan pengetahuan para siswa, tentang tekhnik pengambilan gambar poto dan video manusia, benda dan objek bergerak lain, untuk kepentingan jurnalistik. Selain itu para siswa juga mengenal adanya Citizen Journalism, jurnalistik kewargaan.
\end{abstract}

Kata Kunci: Smartphone, Jurnalistik, Siswa 
Latar Belakang Masalah

Ponsel tidak lagi menjadi barang mewah sehingga kebutuhan ponsel cerdas (smartphone) semakin tinggi. Smartphone merupakan telepon genggam yang mempunyai kemampuan tinggi seperti komputer dikarenakan smartphone juga mempunyai Sistem Operasi yang menjalankannya. Para pengembang smartphone terus berinovasi dengan menambahkan fitur yang semakin beragam dan menjadikan smartphone sebagai perangkat yang dapat melakukan berbagai fungsi (multitasking) hal ini pula yang memicu minat masyarakat untuk memiliki smartphone untuk membantu kebutuhan pekerjaan yang menuntut kecepatan dan multifungsi.

Selain kamera, fitur perekaman video di smartphone telah mengalami peningkatan dibandingkan dengan ponsel-ponsel terdahulu. Karena itu, tak jarang seseorang memanfaatkan perangkat smartphone-nya untuk mengambil video. Selain lebih mudah dan ringkas, video yang direkam juga bisa langsung diedit ataupun diunggah melalui aplikasi yang tersedia.

Perkembangan pengguna smartphone sangat pesat di Indonesia. Menurut Djatmiko Wardoyo selaku Marcomm Director Era Jaya di mulai tahun 2008 jumlah pengguna smartphone di Indonesia hanya 2\%. Mengutip data yang dimiliki oleh eMarketer, Sabtu (19/9/2015), diperkirakan pada 2016 hingga 2019 pengguna smartphone di Indonesia akan terus tumbuh. Angka pertumbuhannya pun fantastis. Pada 2016 akan ada 65,2 juta pengguna smartphone dan di tahun 2017 akan ada 74,9 juta pengguna. Adapun pada 2018 dan 
2019 , terus tumbuh mulai dari 83,5 juta hingga 92 juta user smartphone di Indonesia . Data ini menggambarkan kepemilikan dan penggunaan smartphone di Indonesia dari tahun ke tahun terus bertambah, namun apakah penggunaannya untuk hal yang bermanfaat dan produktif seperti menggunakan fitur rekaman suara dan video.

Kehadiran smartphone juga memperluas kesempatan kepada khalayak untuk mempraktekkan jurnalisme kewargaan. Siapapun bisa meliput dan kemudian menyebarluaskan berita. Spektrum berita terutama di dunia maya menjadi sangat luas. Lewat berbagai aplikasi sosial media setiap orang bisa menjadi pewarta, menyampaikan kabar pada lingkaran perkawanannya yang kemudian menyebar apabila mereka yang menerima kabar kemudian turut berbagi berita.

\section{Gambar 1.1}

\section{Persentase khalayak mengakses} berita melalui ragam media.

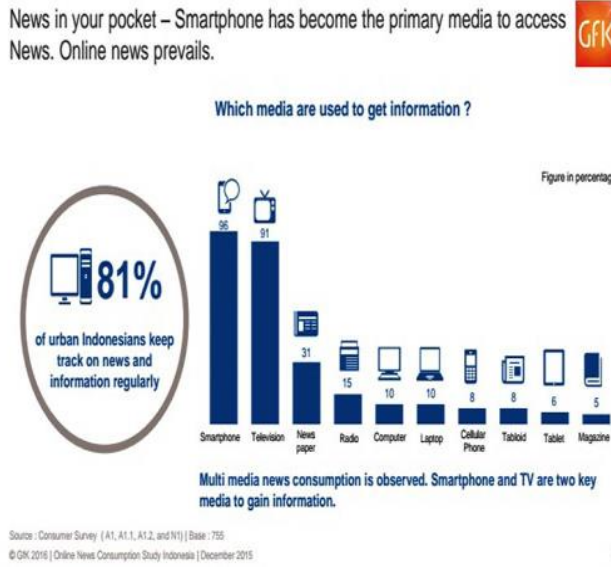

Foto Sumber : Indonesian Digital Association (IDA)

Data temuan dari riset Indonesian Digital Association (IDA), yang didukung oleh Baidu Indonesia, dan dilaksanakan oleh lembaga riset global GfK menyebutkan, masyarakat perkotaan Indonesia menggemari konsumsi berita melalui telepon genggam (smartphone). Persentasenya mencapai 96 persen yang merupakan angka tertinggi dibandingkan media lain seperti televisi 91 persen, surat 
kabar 31 persen serta radio 15 persen

dan

lainnya.

(https://techno.okezone.com) Namun

akurasi, verifikasi atau penelusuran

yang lebih dalam menjadi tantangan

tersendiri dalam jurnalisme

smartphone.

Smartphone dengan segala

kelebihannya tentu saja patut

disyukuri karena membuka

kesempatan yang lebih luas untuk

melakukan pemberitaan kewargaan

(citizen jurnalism). Namun yang

perlu disadari berita bukan sekedar

untuk memenuhi kebutuhan akan

sensasi atau kontroversi belaka.

Onong Uchjana Effendy, dalam

bukunya Ilmu, Teori dan Filsafat

Komunikasi 1993, menyebutkan,

jurnalistik adalah teknik mengelola

berita mulai dari mendapatkan bahan

sampai menyebarluaskannya kepada

masyarakat.
Maka dari itu, di balik

kecanggihan teknologi tetap

dibutuhkan seseorang di belakangnya

untuk memastikan kualitas video

tetap baik dan berkualitas bagus.

Berita atau informasi diperlukan

untuk menyehatkan kehidupan

bermasyarakat, menambah

pengetahuan, menyadarkan akan

risiko atau ancaman tertentu serta

memberi hiburan menyegarkan.

https://www.kompasiana.com/yustin

$\underline{\text { us_sapto }}$

Smartphone sudah dimiliki

oleh hampir setiap orang disemua kalangan, dimulai dari anak-anak sampai orang yang sudah lanjut usia pun sudah menggenggam telephone ini. Namun penggunaan semartphone yang semakin meluas tentu saja tidak lepas dari dampak positif maupun dampak negative bagi penggunanya, terutama bagi pelajar. 
Ada beberapa dampak positif penggunaan smartphone bagi pelajar antara lain:

1. Memudahkan dalam mengakses informasi secara luas dan cepat

2. Memudahkan

dalam

berkomunikasi, terutama jika

digunakan untuk membuat forum diskusi

3. Menambah wawasan pengetahuan pelajar karena mudahnya mencari informasi

Adapun dampak negative penggunaan semartphone bagi pelajar antara lain:

1. Menjadikan pemakainya malas, hanya mengandalkan smartphone.

2. Melemahkan otak penggunanya, karena mudahnya dalam mencari informasi pelajar malas untuk berfikir

3. Mengganggu kesehatan penggunanya, terutama kesehatan mata
4. Menbuat penggunanya kecanduan sosmed (social media), game, serta aplikasi-alikasi lainnya

5. Membuat boros, karena penggunaan smartphone yang tidak lepas dari internet menyebabkan pemakaian pulsa berlebih

6. Memungkinkan pelajar untuk mengakses hal-hal yang tidak seharusnya diakses seperti video porno.

Dampak negatif yang cukup banyak, menjadi ironi saat hampir semua pelajar SMA saat ini bisa dipastikan memiliki smartphone dan menggunakannya untuk aktifitas sehari hari, di rumah dan di sekolah. Karena pertimbangan itulah, penulis merasa penting melakukan sosialisasi dan pelatihan, agar fasilitas alat komunikasi smartphone yang ada dan dimiliki para pelajar SMA Negeri 4 dan SMA Kartika I-2 
Medan, dapat dimanfaatkan secara

baik, positif, tepat, benar dan bahkan

dapat mengembangkan bakat dan

kemampuan jurnalistik pada siswa

SMA.

Metode Penelitian

Kajian

mengenai

Pemanfaatan smartphone dalam

meningkatkan kemampuan

jurnalistik di kalangan siswa SMA

Negeri 4 Medan SMA Kartika I-2

Medan pendekatan deskriptif

kualitatif studi kasus pada siswa

kelas 10 di SMA Negeri 4 Medan

dan siswa kelas 10 SMA Kartika I-2

Medan. Pendekatan kualitatif

Menurut Kriyantono (2012) dapat

berupa kata-kata, kalimat-kalimat

atau narasi-narasi, baik yang

diperoleh dari wawancara mendalam

maupun observasi.

Hal demikian senada dengan

yang disampaikan Moleong (2007) yang mengatakan bahwa deskriptif kualitatif adalah sebagai prosedur penelitian yang menghasilkan data deskriptif berupa kata-kata tertulis dan lisan dari orang-orang dan perilaku yang dapat diamati.

Studi kasus merupakan bagian penelitian dari penelitian kualitatif, yang mendalam tentang individu, satu kelompok, satu organisasi, satu program kegiatan, dan sebagainya dalam waktu tertentu. Tujuannya untuk memperoleh diskripsi yang utuh dan mendalam dari sebuah entitas. Sebagaimana prosedur perolehan data penelitian kualitatif, data studi kasus diperoleh dari wawancara, observasi, dan arsip.

\section{Hasil Penelitian dan Pembahasan}

$$
\text { Penelitian }
$$

mengenai

peningkatan pengetahuan jurnalistik siswa SMA melalui pemanfaatan 
smartphone, studi kasus pada siswa

kelas 10 SMA Negeri 4 Medan dan

SMA Kartika I-2 Medan ini dimulai dengan mengumpulkan data awal, berapa lama mereka telah menggunakan smartphone.

Ditemukan $\quad 95 \%$ siswa telah menggunakan smartphone dengan rerata selama 3-5 tahun. Namun hanya sebatas penggunaan kepentingan individu atau pribadi.

Masing masing siswa menggunakan smartphone yang memiliki fitur lengkap, foto/kamera, audio, video dan menggunakan paket data seluler yang cukup besar. Rerata fitur foto dan video digunakan untuk swapoto atau selfie / welfie. Hanya di publish di media social, what's up, facebook dan instagram. Fitur video, hanya di gunakan merekam shoot yang sangat singkat, masih tetap lebih bersifat pribadi. Masih tetap di upload ke semua media social yang dimiliki para siswa. Namun, mereka tidak peduli pada komentar, like , atau viewers, terhadap konten foto dan video yang mereka upload itu. Fitur audio malah sangat jarang digunakan.

Padahal para siswa itu, melalui proses wawancara dengan peneliti, menyebutkan bahwa mereka banyak tahu dan jadi pengikut (follower) akun berita di internet, yang bisa jadi tempat meletakkan audio, foto dan video, sebagai sumber informasi bagi orang banyak / khalayak. Seperti akun Medan Talk dan Kompas Online. Bahkan ada siswa yang jadi follower akun milik pengacara terkenal, Hotman Paris Hutapea. Mulanya siswa tertarik mengikuti akun itu, karena memuat informasi secara terus menerus, mengenai kasus bullying terhadap seorang siswi SMP di Kalimantan. Merasa bahwa akun itu bisa jadi 
sumber informasi bagi dirinya, yang

masih pelajar SMA. Nilai berita

Proximity, Conflict dan Human

interest ada didalamnya. (Deddy

Iskandar Muda, 2003)

Karena pertimbangan itulah, sosialisasi dan pelatihan menjadi penting, agar fasilitas alat komunikasi smartphone yang ada dan dimiliki para pelajar SMA Negeri 4 dan SMA Kartika I-2 Medan, dapat dimanfaatkan secara baik, positif, tepat dan benar untuk mengembangkan bakat dan kemampuan jurnalistik pada siswa SMA.

Untuk mengetahui pengetahuan jurnalistik siswa SMA negeri 4 Medan dan SMA Kartika I2 Medan, para siswa menjawab pertanyaan yang sama untuk Pra Test dan Post test. Pertanyaan Pra Test diberikan sebelum melewati tahapan sosialisasi, yaitu ;
1. Tahapan pengenalan dan pemahaman, ditahap ini siswa di jelaskan apa saja fitur fitur dan kelebihan smartphone dan bagaimana pemanfaatan di bidang jurnalistik. Tahapan ini juga akan memberikan penjelasan teori jurnalistik, jenis jenis karya jurnalistik kepada peserta pelatihan.

2. Tahap pendidikan dan pelatihan

a) Tekhnik penulisan naskah berita, versi internet, audio dan audio visual

b) Tekhnik peliputan berita internet, audio dan audio visual

c) Tehknik pengambilan gambar untuk video jurnalistik

d) Tekhnik editing audio dan visual 
Pada tahapan pendidikan

dan pelatihan ini, siswa

dibimbing tentang tata cara

pemanfaatan smartphone

demi

meningkatkan

kemampuan jurnalistik dan

mengenalkan dunia media

massa kepada kalangan

siswa SMA.

3. Praktek kerja

Setelah mengikuti sosialisasi, pelatihan dan diskusi, maka siswa diminta untuk memanfaatkan smartphone yang mereka miliki, untuk mengambil foto dan video, yang sesuai teknik jurnalistik dasar. Hal ini dilakukan agar dapat mengukur tingkat pemahaman siswa mengenai jurnalistik dan proses kerja jurnalistik dengan memanfaatkan smartphone.

\section{Penutup}

Berdasarkan hasil sosialisasi dan penelitian, menunjukkan adanya peningkatan kemampuan jurnalistik siswa melalui pemanfaatan smartphone di kalangan Siswa SMA Negeri 4 Medan dan SMA Kartika I2 Medan. Dari awalnya mereka tidak tahu menjadi paham atau sangat paham, akan manfaat smartphone untuk membuat video dan foto jurnalistik sebagai media pendukung aktifitas jurnalistik dasar kewargaan. Para siswa memahami bahwa apa yang mereka lakukan sehari hari dengan smartphonenya, seperti foto selfie, video aktivitas dan tik tok, bisa di maksimalkan menjadi foto dan video jurnalistik. Semisal, pengambilan poto dan video pada saat di kota wisata Berastagi. Bahkan jika tekhnik pengambilan gambarnya sesuai yang diarahkan saat sosialiasasi dan pelatihan, 
kemungkinan dapat di uplot ke website berita di internet maupun media social, seperti you tube. Tidak hanya kemampuan jurnalistik yang bertambah, namun pemanfaatan smartphone untuk membuat poto dan video jurnalistik, dapat dijadikan profesi baru, atau pekerjaan baru, yang mungkin akan menjadi sumber penghasilan dari para siswa di masa depan.

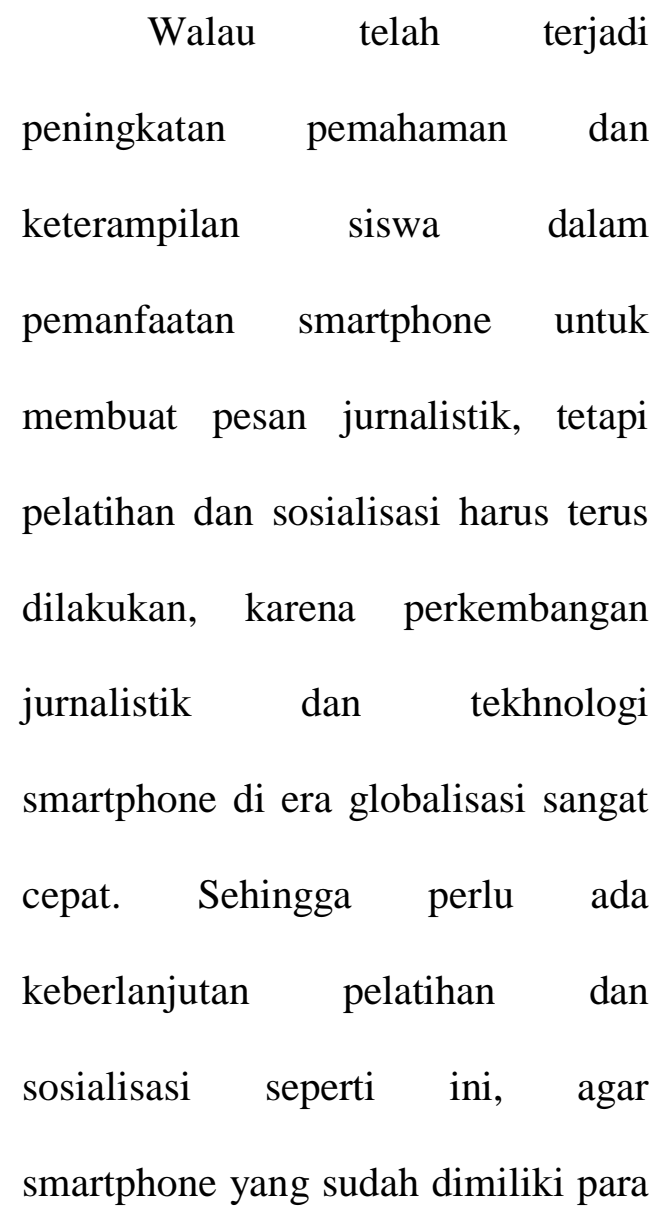

siswa, bisa jadi tools yang bermanfaat, tidak hanya untuk kepentingan pribadi, namun juga bernilai professional.

\section{Daftar Pustaka}

A.S. Haris Sumadiria. 2005. Jurnalistik Indonesia, Menulis berita dan feature, panduan Praktis Jurnalis professional. Bandung: Simbiosa Rekatama Media.

Deddy Iskandar Muda. 2003. Junalistik Televisi, Menjadi Reporter Profesional. Bandung: PT.Remaja Rosdakarya,

Malau, Ruth Mei Ulina. 2011. Khalayak Media Baru. THE MESSENGER. Vol II No. 2 (Januari 2011): 51-56.

Onong Uchjana Effendy. 1993. Ilmu, Teori dan Filsafat Komunikasi. Bandung: $\quad$ PT.Remaja Rosdakarya

Situmorang, James R. 2012. Pemanfaatan Internet Sebagai New Media Dalam Bidang Politik, Bisnis, Pendidikan dan Sosial Budaya. Jurnal Administrasi Bisnis, Vol 8 No 1 (2012): 73:87.

Wardoyo, Djatmiko.Tiap 8 Bulan Orang Indonesia Ganti Smartphone. 16 Januari 2013.http://inet.detik.com/read/ diakses 05 November 2018 /tiap-8-bulanorang-indonesiaganti-smartphone. 
https://www.kompasiana.com/omi/pe ngaruh-smartphone-bagi-

kehidupan-pelajar, di posting pada 07 Maret 2016/ diakses 05 November 2018

https://www.liputan6.com/tekno/read /3582281/5-tips-merekamvideo-ala-profesional-dismartphone-android di posting 09 Juli 2018, diakses 05 November 2018

https://www.kompasiana.com/yustin us_sapto/jurnalisme-smartphone di posting 17 Juni 2015 , diakses 05 november 2018

https://techno.okezone.com/readpersen-pengguna-smartphonetertinggi-ada-di-indonesia, diposting 16 Maret 2016, diakses 06 November 2018 